\title{
A VIGOR MEASUREMENT METHOD \\ FOR DETERMINING TRENDS IN THE \\ CONDITION OF KEY FORAGE BUNCHGRASSES \\ ON MONTANA ELKK RANGES
}

by

\author{
GIen F. Cole \\ fiange Biologist \\ Montana Department of Fish and Game \\ Helena, Montana
}

Report from Project W-37-R-8
Aprii 1, 1957 
-

-

- 
Use of the Method 4

Materials Used 4

Period and frequency of use

Use on seasonal ranges

Selection of a key forage bunchgrass

Selection of sites for using the method

Establishment of plots on sites

Number of plots established

Procedure for laying out a plot

Numbers of plants selected for measurement

Procedure for selecting plants to be measured

Figure 1. - Physical features of a plot

Vigor measurements obtained from plants

Units of measurement

Procedures of measurement

Time required to lay out and measure a plot

Figure 2. - Field form for recording measurements

Figure 3. - Bunchgrass form classes 11

Compilation of data 12

Reliability standards for form class percentages

Reliability standards for means

Procedure for calculating additional numbers of plants needed to satisfy reliability standards 
-

-

- 
Page Section

Procedure for comparing initial and subsequent form class percentages

Procedure for comparing initial and subsequent basal area and leaf height means

Analysts of data

Possible extensions in the method

Table 1. $-95 \%$ confidence intervals

Table 2. - Chi-square values 19

Table 3. - t-values 19

Literature Cited 
-

-

- 
A VIGOR MEASUREMENT METHOD FOR DETERMINING TRENDS IN THE

CONDITION OF KEY FORAGE BUNCHGRASSES ON MONTANA ELK RANGES 1

\author{
Glen F. Cole
}

Introduction

The method is a procedure for measuring the vigor of key forage bunchgrasses. Initial and subsequent vigor measurements are compared to determine trends in bunchgrass condition.

On the ranges where the method has been used, Idaho fescue (Festuca idahoensis) was selected as a key forage bunchgrass. Selection was based on observations of elk use and measurements of plants inside and outside exclosures. This bunchgrass appears to be very palatable to elk and on most Montana ranges it is abundant enough to serve as an important forage source. Buechner (1952) concluded that Idaho fescue was a preferred elk forage on a winter range in Washington.

The ecological basis for the method was suggested from a review of literature on grass responses to herbage removals (Blaisdell and Pechanec 1949, Heady 1950, Evanco and Peterson 1955, and others). Sampling procedures were designed with the assistance of Dr. Bernard Ostle, Professor of Mathematics, Montana State College. The method was used by the author and other personnel of the Montana Fish and Game Department during 1956. Revisions and extensions were made on the basis of field observations and measurements. While it has had only limited use, the method is indicated to be suitable for measuring short term trends in bunchgrass condition. Additional revisions and extensions are expected as more experience is gained. Use of the method is described here so that others may use it as it is, or modify it to suit their own conditions.

\title{
Use of the Method
}

\section{Materials used.}

The materials needed to use the method are as follows:

I steel rule graduated in tenths of inches

1 one hundred foot tape

1 surveyor's compass

1 six pound hammer

I six foot steel post and four 18 inch steel stakes

for each plot established

12 sharpened wood laths

$I_{A}$ contribution from Federal Aid in Wild]ife Restoration, Montana Project $W-37-R$. Thanks are extended to Dr. Bernard Ostle for reviewing the report. 
-

0

0 
The compass is used to maintain right angles on plot corners. The 100-foot tape may also be used to maintain right angles. Distances of 15, 20, and 25 feet are used to form the three sides of a right triangle.

2. Period and frequency of use.

The method is used after bunchgrass plants have matured and before the plants are covered by snow. This period is roughly between August 1.5 and October 15 in Montana. Annual or biennial measurements are recommended.

3. Use on seasonal ranges.

The method may be used as described on ranges grazed during the spring, fa.17 and winter. On ranges grazed during the summer, take-down exclosures must be employed to protect the plants to be measured.*

4. Selection of a key forage bunchgrass.

A key forage bunchgrass should be palatable to elk, serve as an important source of forage and have a definite bunchgrass life form. In practice, proper use on a key forage bunchgrass should reflect proper use, or something less than proper use, on other important forage grasses.

The palatability of a bunchgrass may be indicated by recording frequencies of plant use at elk feeding sites (Brazda 1953). The importance of a palatable bunchgrass as a forage source may be indicated by observations of abundance or by forage inventory methods such as clipping or weight estimates (Pechanec and Pickford 1937). Suitability of bunchgrass Ifife forms is determjned by observation. Bunchgrass clumps should be compact units which have definite basal areas. Some of the bunchgrasses found to have suitable life forms on Montana elk ranges were Idaho fescue, rough fescue (Festuca scabrella), and bluebunch wheatgrass (Agropyron spicatrm).

5. Selection of sites for using the method.

Sites where a key forage bunchgrass is furnishing forage to elk are selected on key areas of elk range. Selections may be based on observed use of the sites by elk or on indications of use from plant utilization and/or pellet groups.

6. Establishment of plots on sites.

Permanent 100 by 250 foot plots are established on selected sites. Care is taken that each plot represents an ecological entity such as a ridge top, slope or flat. This is necessary to isolate plant variations due to differences in soil or moisture relations.

7. Number of plots established.

The number of plots established on a range is left to the discretion of management personnel. The different vegetational types and the pattern

* See 22 (Possible extensions of the method). 
-

- 
of $\mathrm{e}$ Ik use should be considered. Costelilo and KIipple (1.939) point out that nubers of sample plots are dependent upon the heterogents:ty of the vegetation on an area rather than the size of an area. The pattern of elk use on ranges is uneven. Areas where forage recelves heavy, moderate ox lifght use are usually evident. Relatively few plots will be required if they are strategically located within one vegetational type on heavily us.sed areas. The forage on these heavily used areas should represent a food source which must be maintained in a productive condition. As few as s.x plots have been used on a 4,000 acre winter elk range in Montana.

8. Procedure for laying out a plot.

The physical features of a plot are shown on figure I. In laying out a plot a 300-woot base line, where the 50 to 300 foot distance represents one side of the plot, is measured. As the base line is mes,sured the following markers are driven into the ground: a six-foot steel post. at the zero foot mark, an 18-inch steel stake and a wood lath at the 50 foot mark, a wood lath at the 100, 150, 200 and 250 foot marks, an 18inch steel stake and a wood lath at the 300 foot mark.

At the 300 foot mark a 100 foot line is extended 90 degrees from the horizontal base line. This forms the second side of the plot. To form the third side a 250 foot line, parallel to the base line, is measured. As this line is measured the following markers are driven into the ground: an 18-inch steel stake and a wood lath at the zero foot mark, a wood lath at the $50,100,150$ and 200 foot marks, an 18-inch steel stake and a wood Iath at the 250 foot mark. This completes the plot which is outlined by the four 18-inch steel stakes. The offset six--foot steel post and the four 18-inch stakes serve as permanent markers. The wood laths serve to divide the plot into five 50 by 100 foot sections. The laths are removed after the plants on a plot have been measured.

9. Numbers of plants selected for measurement.

Init:2.11y, $100 \mathrm{key}$ bunchgrass plants are selected for measurement on each plot. If the data from one plot, or from groups of plots, does not meet reliability standards (see 17 and 18), additional plants are selected for measurement. The procedure for selecting plants may be easily modified to select the desired number。

10. Procedure for selecting plants to be measured.

The procedure requires that a specified course be followed and that a designated number of steps be taken before each plant is selected.

The course followed is shown on figure I. The wood laths are used as guide posts for walking the crossing diagonal course through each section. The stariting point is the corner closest, to the six foot steel posto If additional plants are needed after one passing through a plot, the course is retraced (in an opposite direction) until the full 100 plants are selected. 
-

-

- 


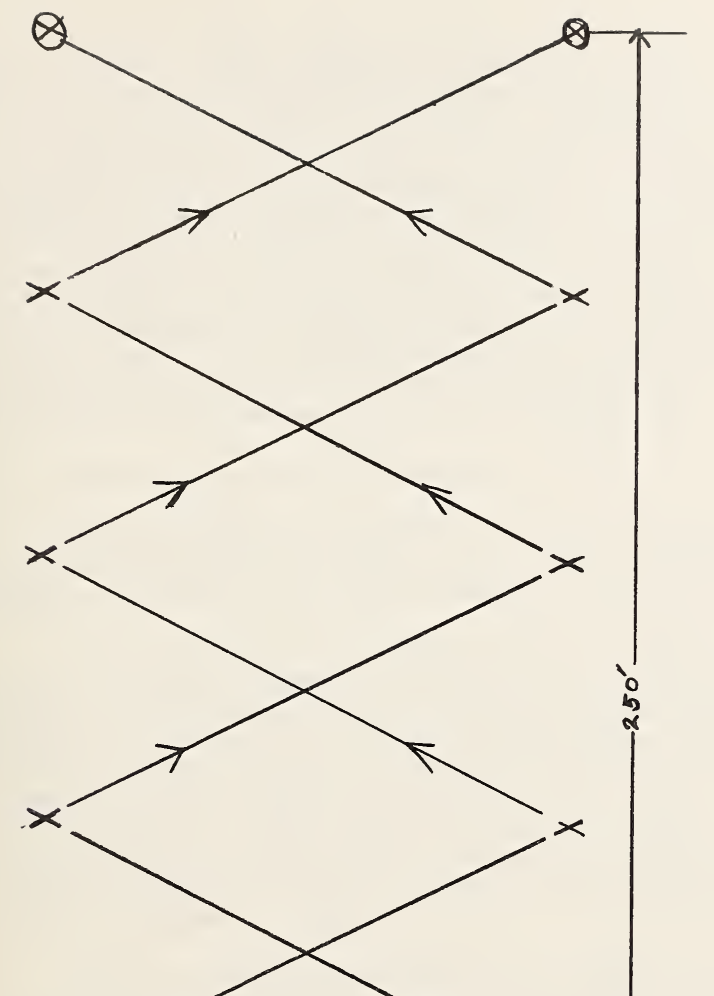

.

a $x$

념

त्ञ

क छี

글 岂

్ํ

๙

号

덜

ड

वृ तี

党

용

จ.न

क्ष

ठำ

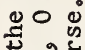

मे है

모웡

ส

茞 吅

음

む

응 త్ర

น ญ ڤ

신

넹

ف용

8 덩

-

त)

फ

을

०

\& 6

ฟึ) हैं

$4-1$ (a)

거욤

0 엇

, D

언

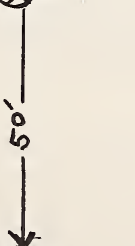

ही

¿-1

(a) 
-

-

- 
The steps taken, while following the specified course, range from one to seven. Their sequence is determined from a table of random numberso Steps are counted from the corner starting point or from points where a previous plant was measured. The number of steps taken before selecting each of the 100 plants is shown on the field form (figure 2). The key bunchgrass plant closest to the toe of the foot completing the des:ignatied number of steps is selected. If this plant has a form classed a.s Normal, Hollow Center or Clump Edge (see 11, on bunchgrass form classes), it is measured. If the plant has a form classed as Seedling or Dead, it is dotwtallied and the next closest Normal, Hollow Center or Clump Edge plant is measured. A penciled circle is then drawn around the form class of this plant. If the random sequence of steps from one to seven fails to sample all portions of a plot or consistently causes the course to be retraced, the range of steps may be adjusted.

11. Vigor measurements obtained from plants.

The measurements considered to reflect the vigor of bunchgrasses are shown on the field form (figure 2). They are bunchgrass form classes, lengths and width of bunchgrass clumps and maximum leaf heights.

The form classes are Normal, Seedling, Hollow Center, Clump Edge and Deado The Normal class is assigned if all portions of a bunchgrass clump produce leaves (figure 3A), the Seedling class if the length $\mathrm{x}$ width measurement is 0.6 inch or less, the Hollow Center class if a "ring" of leaves encireles a dead center by more than one-half the clump circumference (figure 3B), the Clump Edge class if one or more segments of Ieaves grow on the edge of a clump (figure 3C) and the largest segment does not encircle more than one-half the clump circumference. Segments are cons.dered separate if they are 0.3 inch from other segments. The Dead class is assigned to plants which do not produce leaves.

Recent or decomposed suffixes are assigned to Hollow Center, Clump Edge and Dead form classes. The recent suffix (R) is assigned if oid Ieaf structure is evident on the dead portion of a bunchgrass clump. The decomposed suffix. (D) is assigned if old leaf structure is not evidento

12. Units of measurement.

Lengths and widths of bunchgrass clumps and maximum leaf heights are measured to the nearest 0.1 inch. Form classes are assigned.

13. Procedures of measurement.

Two opposed length and width measurements are made through the basal. portion of each Normal and Hollow Center plant and the largest segment of each Clump Edge plant. Maximum leaf heights are measured by placing a mie vertically within a bunchgrass clump or segment. Form classes are assigned by observation.

140 Time required to lay out and measure a plot.

Two men are able to lay out a plot in 15 to 20 minutes. With one man recording and another measuring, approximately one and one-quarter to one and one-half hours are required to obtain the various measurements from 100 plants. 


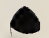

- 
GRASS VIGOR MEASUREMENT FORM

D:stricet.

Area.

Type

Location

Form Classes

$\mathrm{N}=$ NormaI

$\mathrm{S}=$ Seedling

$\mathrm{HC}=$ Hollow Center*

$\mathrm{CE}=$ Clump Edge $\mathrm{E}^{*}$

$\mathrm{D}=$ Dead $^{*}$

*Add recent (R) or decomposed (D) suffixes

Plant No. Form Basal Area Index

\begin{tabular}{c|c|c|c}
$\begin{array}{c}\text { Plant } \\
\text { No. }\end{array}$ & $\begin{array}{c}\text { Noo } \\
\text { Steps }\end{array}$ & $\begin{array}{l}\text { Form } \\
\text { Class }\end{array}$ & $\begin{array}{c}\text { Basal Area Index } \\
\text { Length Width IxW }\end{array}$ \\
\hline
\end{tabular}

$-1$

$\frac{2}{3}$ Width IexW

\begin{tabular}{c|c} 
Max. & Max $)^{2}$ \\
Leaf Ht。
\end{tabular} Examiners

Dot Tally

Seedlings

Dead $R$

\begin{tabular}{c|c}
2 & 4 \\
\hline 3 & 3 \\
\hline 4 & 5 \\
\hline 5 & 2 \\
\hline 6 & 7 \\
\hline 7 & 5 \\
\hline 8 & 3 \\
\hline 10 & 4 \\
\hline$\frac{71}{12}$ & 5 \\
\hline 13 & 3 \\
\hline 11
\end{tabular}

1.4

15

16

17

18

19

20

$2]$

22

23

24

25

26

27

28

29

30

31

32

33

34

$\frac{5}{4}$

$\frac{3}{2}$

$\frac{7}{5}$

35

$\frac{\frac{6}{5}}{\frac{3}{7}}$

$\frac{\frac{5}{3}}{\frac{7}{5}}$

$\frac{1}{2}$

$\frac{1}{6}$

$\frac{5}{7}$

$\frac{7}{5}$

$\frac{2}{6}$

3

$\frac{3}{4}$

$\frac{4}{6}$

6

1

$\frac{1}{7}$

$\frac{7}{2}$

$\frac{37}{38}$

$\frac{38}{39}$

40

$\frac{47}{42}$

$\frac{42}{43}$

$\frac{41}{45}$

$\frac{\frac{4}{3}}{\frac{7}{6}} \frac{6}{\frac{7}{5}}$

$-1$


GRASS VIGOR MEASUREMENT FORM

$$
\begin{aligned}
& \text { Plot No. } \\
& \text { Date }
\end{aligned}
$$

\begin{tabular}{|c|c|c|c|c|c|c|c|c|}
\hline $\begin{array}{l}\text { Plant } \\
\text { No. }\end{array}$ & No. & Form & $\mathrm{Ba}, \mathrm{sa}$ & Area Ir & lex & & $\operatorname{Max}_{0}$ & \\
\hline No. & Steps & Class & Length & Width & IxW & $(L x W)^{2}$ & & $($ Leaf Hto) \\
\hline 46 & 6 & & & & & & & \\
\hline 47 & 3 & & & & & & & \\
\hline 48 & 7 & & & & & & & \\
\hline 49 & 7 & & & & & & & \\
\hline 50 & 4 & & & & & & & \\
\hline 51 & 1 & & & & & & & \\
\hline 52 & 5 & & & & & & & \\
\hline 53 & 4 & & & & & & & \\
\hline 54 & 1 & & & & & & & \\
\hline 55 & 6 & & & & & & & \\
\hline 56 & 1 & & & & & & & \\
\hline 57 & 4 & & & & & & & \\
\hline 58 & 4 & & & & & & & \\
\hline 59 & 5 & & & & & & & \\
\hline 60 & 2 & & & & & & & \\
\hline 61 & 5 & & & & & & & \\
\hline 62 & 3 & & & & & & & \\
\hline 63 & 2 & & & & & & & \\
\hline 64 & 7 & & & & & & & \\
\hline-65 & 2 & & & & & & & \\
\hline 66 & 1 & & & & & & & \\
\hline 67 & 7 & & & & & & & \\
\hline 68 & 7 & & & & & & & \\
\hline 69 & I & & & & & & & \\
\hline 70 & 5 & & & & & & & \\
\hline 71 & 5 & & & & & & & \\
\hline 72 & 5 & & & & & & & \\
\hline 73 & 2 & & & & & & & \\
\hline 74 & 2 & & & & & & & \\
\hline 75 & 1 & & & & & & & \\
\hline 76 & 5 & & & & & & & \\
\hline 77 & 6 & & & & & & & \\
\hline 78 & 3 & & & & & & & \\
\hline 79 & 3 & & & & & & & \\
\hline 80 & 2 & & & & & & & \\
\hline 81 & 4 & & & & & & & \\
\hline 82 & 5 & & & & & & & \\
\hline 83 & 3 & & & & & & & \\
\hline 84 & 6 & & & & & & & \\
\hline 85 & 5 & & & & & & & \\
\hline 86 & 2 & & & & & & & \\
\hline 87 & 1 & & & & & & & \\
\hline 88 & 5 & & & & & & & \\
\hline 89 & 1 & & & & & & & \\
\hline 90 & 4 & & & & & & & \\
\hline 91 & 1 & & & & & & & \\
\hline 92 & $I$ & & & & & & & \\
\hline 93 & 2 & & & & & & & \\
\hline 94 & 6 & & & & & & & \\
\hline 95 & 6 & & & & & & & \\
\hline 96 & 4 & & & & & & & \\
\hline 97 & 1 & & & & & & & \\
\hline 98 & 7 & & & & & & & \\
\hline 92 & 6 & & & & & & & \\
\hline 100 & 7 & & & & & & & \\
\hline
\end{tabular}



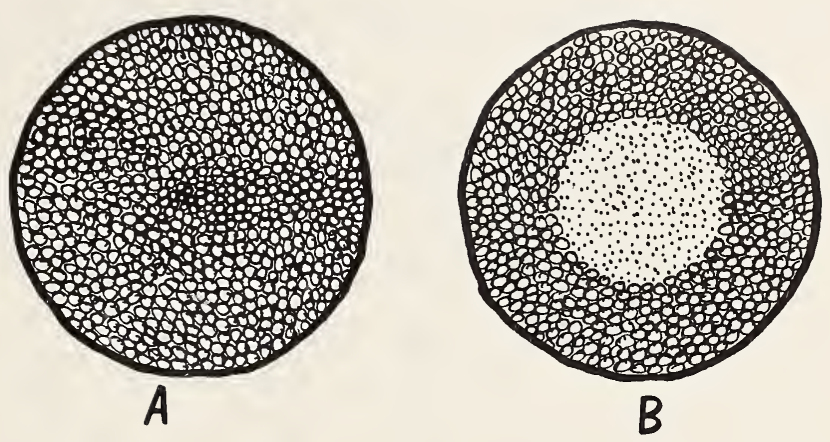

Leaves

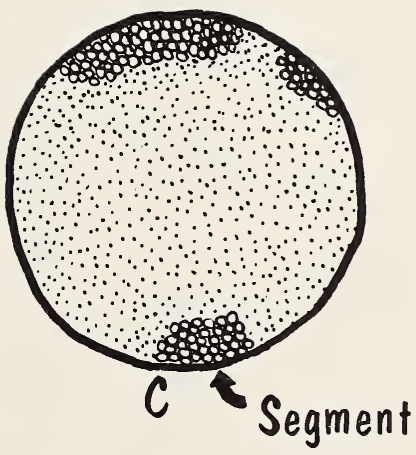

Dead portions of bunchgrass clumps

FIGURE 3 BUNCH GRASS FORM CLASSES
A. Normal
B. Hollow Center
C. Clump Edge 
Data from one plot or groups of plots may be compiled.

Individual form classes are totaled, discounting those circled (selected as alternatives to the Seedling or Dead Classes). Results are expressed as percentages.

Length and width values for each Normal, Hollow Center and Clump Edge plant are multiplied to give a basal area index. The basal area index and leaf height values for these plants are totaled. Results are expressed as means plus or minus their standard errors.

Means and standard errors are computed by calculating:

$$
\bar{Y}=\frac{\sum Y}{n} \text { and } S_{\bar{Y}}=\sqrt{\frac{S^{2}}{n}}
$$

where

$\bar{Y}=$ the mean of basal area or leaf height values

Y $=$ the individual basal area or leaf height values

$\mathrm{n}=$ the number of plants measured

$S_{\bar{Y}}=$ the standard error of the basal area or leaf height means

$S^{\frac{1}{2}}$ the sample variance

The sample variance $\left(S^{2}\right)$, where the data are from one plot, is calculated from the formula

$$
S^{2}=\frac{\sum Y^{2}-\frac{\left(\sum Y\right)^{2}}{n}}{n-1}
$$

Where the data are from groups of plots, the pooled estimate of variance is given by

$$
s^{2}=\frac{\left(n_{1}-1\right) s_{1}^{2} \ldots\left(n_{g}-1\right) s_{g}^{2}}{\left(n_{1}-1\right) \ldots\left(n_{g}-1\right)}
$$

where

$S_{i}^{2}$ - the sample variance of the $i$ th plot $(i=1,2, \ldots, g)$

$n_{i}=$ the number of plants measured in the ith plot $(i=1,2, \ldots, 8)$

16. Reliability standards for form class percentages.

Confidence limits are used to indicate the reliability of form class pereentages. In detemining confidence limits consult table 1 in the appendix where 
$\mathrm{P}$ - the percentage of a class

$L_{I}=$ the lower 95 per cent confidence limit

$\mathrm{L}_{2}=$ the upper 95 per cent confidence limit

$\mathrm{n}=$ the sample size

Results are expressed as $P\left(I_{7}-I_{2}\right)$

Example: A group of ten plots had 1,000 plants classified as follows:

\begin{tabular}{lrrrrr}
\multicolumn{1}{c}{ Class } & No. Plants & $\mathrm{P}$ & $\mathrm{I}_{7}$ & \multicolumn{1}{c}{$\mathrm{I}_{2}$} & Expression \\
Normal & 600 & 60 & 57 & 63 & $60 \%(57-63)$ \\
Seedling & 100 & 10 & 8 & 12 & $10 \%(8-12)$ \\
Hollow Center - R & 125 & 13 & 11 & 15 & $13 \%(17-15)$ \\
Hollow Center - D & 25 & 3 & 2 & 4 & $3 \%(2-4)$ \\
Clump Edge - R & 120 & 12 & 11 & 15 & $12 \%(10-14)$ \\
Clump Edge - D & 10 & 1 & 2 & 4 & $1 \%(0-2)$ \\
Dead - R & 20 & 2 & 0 & 0 & $2 \%(1-3)$ \\
Dead - D & 0 & 0 & 0 & 0 & $0 \%(0-0)$
\end{tabular}

Where sample sizes are other than those shown in table 1 approximate $L$ values for $P$ may be int erpolated.

Example: $\mathrm{n}=400, \mathrm{P}=50$

In table $1, n$ and $L$ values on either side of $n=400$ are:

$\begin{array}{ccc}\mathrm{n} & \mathrm{I}_{1} & \mathrm{I}_{2} \\ 1000 & 47 & 53 \\ 250 & 44 & 56\end{array}$

Differences between the $\mathrm{n}$ and $\mathrm{L}$ values are 750 and 3 respectively. The difference between $n=1000$ and $n=400$ is 600. Therefore,

$$
\frac{600}{750} \times 3=2.4 \text { or } 2
$$

and 47-2 (45) and 53+2 (55) express the $L_{1}$ and $L_{2}$ values where $n=400$ and $P=50$ 。

17. Reliability standards for means.

Standard errors (see 15) are used to indicate the reliability of basal area and leaf height means. Standard errors of a basal area mean should be 10 per cent or less of the mean, of a leaf height mean, 5 per cent or less of the mean. 
18. Procedure for calculating additional numbers of plants needed to satisfy reliability standards.

When standard error percentages indicate that means are not sufficiently reliable, the number of additional plants needed to give the desired reliability is calculated by the formula

$$
N=\frac{s^{2}}{s_{\bar{Y}}^{2}}-n
$$

where

$$
\begin{aligned}
& N=\text { the numbers of additional plants needed } \\
& n=\text { the number of plants measured } \\
& S^{2}=\text { the sample variance (see } 15 \text { ) } \\
& S_{\bar{Y}}=\text { the desired standard error }
\end{aligned}
$$

Example: Measurements from 100 plants gave a basal area mean of 0.96 inches and a standard error of 0.11 inches. This standard error is about 11 per cent of the mean. A standard error of 0.10 inches (10 per cent of 0.96$)$ is desired. The variance $\left(s^{2}\right)$ of the sample was 1.3. These values are inserted in the formula as follows:

$$
N=\frac{1.3}{(0.10)^{2}}-100=30
$$

Therefore, 30 additional plants must be measured to give the desired reliability. In subsequent sampling on the plot, the range of random steps is reduced from one to seven to one to six to permit the selection of thirty additional plants.

19. Procedure for comparing initial and subsequent form class percentages.

Initial and subsequent form class percentages are hypothesized to be similar. A chi-square value is calculated using the formula

$$
x^{2}=\frac{(O-E)^{2}}{E}
$$

where

$$
\begin{aligned}
& x^{2}=\text { the chi-square value } \\
& 0=\text { the observed value } \\
& E=\text { the expected value }
\end{aligned}
$$

and the sumation extends over all classes. 
The calculated chi-square is compared with chi-square values in the proper degrees of freedom ( $\left.d_{\bullet} f_{0}\right)$ row in table 2, Appendix. If the calculated chi-square exceeds the table chi-square in the $\alpha$ column (in the proper d.f. row) the hypothesis is rejected at the $100 \alpha$ per cent significance level.

Example: Initial (1956) and subsequent (1957) form class percentages were as shown below.

\begin{tabular}{|c|c|c|c|c|c|c|c|c|c|}
\hline \multirow{3}{*}{ Year } & \multicolumn{8}{|c|}{ Form Class Percentages } & \multirow{3}{*}{ Totals } \\
\hline & $\overline{\text { Normal }}$ & Seedling & & $\begin{array}{l}\text { Low } \\
\text { ter }\end{array}$ & $\begin{array}{l}\mathrm{Cl} \\
\mathrm{Ed} \\
\end{array}$ & & $\overline{\text { Dead }}$ & & \\
\hline & & & $\underline{R}$ & D & $\underline{R}$ & D & $R$ & D & \\
\hline $\begin{array}{l}1956 \\
1957\end{array}$ & $\begin{array}{l}60 \\
40\end{array}$ & $\begin{array}{r}10 \\
8\end{array}$ & $\begin{array}{l}13 \\
22\end{array}$ & $\begin{array}{l}3 \\
5\end{array}$ & $\frac{77}{15}$ & $\frac{1}{4}$ & $\begin{array}{l}1 \\
4\end{array}$ & $\begin{array}{l}1 \\
2\end{array}$ & $\begin{array}{l}100 \\
100\end{array}$ \\
\hline Totals & 100 & 18 & 35 & 8 & 26 & 5 & 5 & 3 & 200 \\
\hline
\end{tabular}

The observed 1956 and 1957 percentages are hypothesized to be similar. The expected value (E) in any cell is calculated as follows:

$\mathrm{E}=$ (row total $\mathrm{x}$ column total) $\div$ (grand total)

For example the expected value for Normal 1956 is $(100 \times 100) \div(200)=$ 50, Normal 1957 is the same, Seedling 1956 is $(100 \times 18) \div(200)=9$, etco Thus:

$$
\begin{aligned}
x^{2}= & \frac{(60-50)^{2}}{50}+\frac{(40-50)^{2}}{50}+\frac{(10-9)^{2}}{9}+\frac{(8-9)^{2}}{9}+\frac{(13-17.5)^{2}}{17.5}+ \\
& \frac{(22-17.5)^{2}}{17.5}+\frac{(3-4)^{2}}{4}+\frac{(5-4)^{2}}{4}+\frac{(11-13)^{2}}{13}+\frac{(15-13)^{2}}{13}+ \\
& \frac{(1-2.5)^{2}}{2.5}+\frac{(4-2.5)^{2}}{2.5}+\frac{(1-2.5)^{2}}{2.5}+\frac{(4-2.5)^{2}}{2.5}+\frac{(1-1.5)^{2}}{1.5}+ \\
& \frac{(2-1.5)^{2}}{1.5}=11.60
\end{aligned}
$$

Looking in table 2, appendix, in the 7 d.f. row $[$ (No. years -1 ) $x$ (no. classes -1$)=(2-1) x(8-1)]$ our calculated chi-square is seen to exceed the table chi-square value in the .20 $\alpha$ column. Thus the hypothesis of similarity is rejected at the 20 per cent significance level.

20. Procedure for comparing initial and subsequent basal area and leaf height means.

Initial and subsequent means (or any two means) are hypothesized to be similar. A $t$-value is calculated using the formula

$$
t=\frac{\bar{Y}_{1}-\overline{\bar{Y}}_{2}}{\sqrt{\frac{1}{n_{1}} \frac{1}{n_{2}}}}
$$


-

0

0 
where

$$
\begin{aligned}
& \bar{Y}_{1}=\text { the initial mean } \\
& \bar{Y}_{2}=\text { the subsequent mean }
\end{aligned}
$$

and

$$
s=\sqrt{\frac{\left(n_{1}-1\right) s_{1}^{2}\left(n_{2}-1\right) s_{2}^{2}}{\left(n_{1}-1\right)\left(n_{2}-1\right)}}
$$

If the calculated $t$-value is outside a plus or minus range of a t-value (table 3, appendix) in an $n_{1}+n_{2}-2$ degrees of freedom (d.f.) row and a chosen significance level $(\alpha)$ column, the hypothesis of similarity is rejected. If the calculated t-value falls with in the range of plus or minus the t-value, the hypothesis cannot be rejected.

Example: The initial and subsequent means for basal areas where 100 plants were measured each year were 0.82 and 0.61 inches respectively。 The pooled standard deviation (S) was 0.7 .

The means are hypothesized to be similar. Using the formula

$$
t=\frac{.82-.61}{0.7 \sqrt{\frac{1}{100}+\frac{1}{100}}}=2.14
$$

Choosing a one per cent significance level, we observe that 2.14 is within the critical range of plus or minus $t$ in the $0.01 \alpha$ column and the $100+100-2(200)$ d.f. row (table 3, appendix). This t-value is 2.60. Since 2.14 is within this range, we are unable to reject the hypothesis at the one per cent significance level. We note, however, that 2.14 is outside of the range for $t$ in the $.05 \alpha$ column which is -1.97 to +1.97 . Therefore, we are able to reject the hypothesis of similarity at the five per cent significance level.

\section{Analysis of data.}

Trend interpretations from form class percentages depend upon comparisons of initial and subsequent percentages. The degree of confidence in an interpretation is expressed by a significance level at which hypothesis of similarity is, or is not, rejected.

Hollow Center, Clump Edge and Dead form classes are considered to represent stages of deteriorated plant vigor. The suffixes, "R" and "D" are assigned to indicate whether deterioration has resulted from recent or past overuse. Interpretations relative to differences in the Seedling class percentages cannot be made at this writing. The class is considered separately to isolate extremely small basal area measurements which may or may not be influenced by grazing. 
-

-

- 
Trend interpretations from basal area or leaf height, measurements depend upon comparisons of initial and subsequent means. The degree of confidence in an interpretation is expressed by a significance level at which a hypothesis of similarity in means is, or is not, rejected. The basal area index and maximum leaf height measurements are considered to reflect plant vigor.

22. Possible extensions in the method.

On ranges grazed during the summer the method may be used as described with the exception that key bunchgrass leaf heights are not measured。

Where time is a factor, measurement procedures could be simplified to the extent that only the bunchgrass form classes were used. This simplified approach could be used with any acceptable sampling procedure on ranges grazed during any season. In its simplest form an established course could be walked through the area to be sampled. Form classes would be assigned to key bunchgrass plants closest to the toe after completing a specified number of steps.

Key forage grasses on certain ranges may be single stalked species or species which do not grow in compact bunches. Some of these grasses, of possible importance on Montana elk ranges, are western whe atgrass (Agropyron smithii), timber oatgrass (Dathonia unispicata), plains mulley (Mulenburgia cuspidata) and needle-and-thread (Stipa comata). Findings by various authors indicate that measurements of either maximum plant heights or maximum leaf heights will reflect the vigor of these grasses。

An index of key forage grass density may be obtained by measuring the distance between the toe and each of the plants selected by the sampling procedure. 
-

- 
Appendix

Table 1 - 95 Per Cent Confidence Intervals. 1

\begin{tabular}{|c|c|c|c|c|c|c|}
\hline$N=$ & & & & & & \\
\hline $\mathrm{P} *$ & $I_{7}$ & $\mathrm{~L}_{2}$ & $I_{1}$ & $\mathrm{I}_{2}$ & $I_{1}$ & $\mathrm{I}_{2}$ \\
\hline 0 & 0 & 4 & 0 & 1 & 0 & 0 \\
\hline 1 & 0 & 5 & 0 & 4 & 0 & 2 \\
\hline 2 & 0 & 7 & 1 & 5 & 1 & 3 \\
\hline 3 & 1 & 8 & $I$ & 6 & 2 & 4 \\
\hline 4 & 1 & 10 & 2 & 7 & 3 & 5 \\
\hline 5 & 2 & 11 & 3 & 9 & 4 & 7 \\
\hline 6 & 2 & 12 & 3 & 10 & 5 & 8 \\
\hline 7 & 3 & 14 & 4 & 11 & 6 & 9 \\
\hline 8 & 4 & 15 & 5 & 12 & 6 & 10 \\
\hline 9 & 4 & 16 & 6 & 13 & 7 & 11 \\
\hline 10 & 5 & 18 & 7 & 14 & 8 & 12 \\
\hline 11 & 5 & 19 & 7 & 16 & 9 & 13 \\
\hline 12 & 6 & 20 & 8 & 17 & 10 & 14 \\
\hline 13 & 7 & 21 & 9 & 18 & 11 & 15 \\
\hline 14 & 8 & 22 & 10 & 19 & 12 & 16 \\
\hline 15 & 9 & 24 & 10 & 20 & 13 & 17 \\
\hline 16 & 9 & 25 & 11 & 21 & 14 & 18 \\
\hline 17 & 10 & 26 & 12 & 22 & 15 & 19 \\
\hline 18 & 11 & 27 & 13 & 23 & 16 & 21 \\
\hline 19 & 12 & 28 & 14 & 24 & 17 & 22 \\
\hline 20 & 13 & 29 & 15 & 26 & 18 & 23 \\
\hline 21 & 14 & 30 & 16 & 27 & 19 & 24 \\
\hline 22 & 14 & 31 & 17 & 28 & 19 & 25 \\
\hline 23 & 15 & 32 & $\begin{array}{l}1 \\
18\end{array}$ & 29 & 20 & 26 \\
\hline 24 & 16 & 33 & 19 & 30 & 21 & 27 \\
\hline 25 & 17 & 35 & 20 & 31 & 22 & 28 \\
\hline 26 & 18 & 36 & 20 & 32 & 23 & 29 \\
\hline 27 & 19 & 37 & 21 & 33 & 24 & 30 \\
\hline 28 & 19 & 38 & 22 & 34 & 25 & 31 \\
\hline 29 & 20 & 39 & 23 & 35 & 26 & 32 \\
\hline 30 & 21 & 40 & 24 & 36 & 27 & 33 \\
\hline 31 & 22 & 47 & 25 & 37 & 28 & 34 \\
\hline 32 & 23 & 42 & 26 & 38 & 29 & 35 \\
\hline 33 & 24 & 43 & 27 & 39 & 30 & 36 \\
\hline 34 & 25 & 4.4 & 28 & 40 & 31 & 37 \\
\hline 35 & 26 & 45 & 29 & 47 & 32 & 38 \\
\hline 36 & 27 & 46 & 30 & 42 & 33 & 39 \\
\hline 37 & 28 & 47 & 31 & 43 & 34 & 40 \\
\hline 38 & 28 & 48 & 32 & 44 & 35 & 41 \\
\hline 39 & 29 & 49 & 33 & 45 & 36 & 42 \\
\hline 40 & 30 & 50 & 34 & 46 & 37 & 43 \\
\hline 41 & 31 & 51 & 35 & 47 & $38^{\circ}$ & 44 \\
\hline 42 & 32 & 52 & 36 & 48 & 39 & 45 \\
\hline 43 & 33 & 53 & 37 & 49 & 40 & 46 \\
\hline 44 & 34 & 54 & 38 & 50 & 41 & 47 \\
\hline 45 & 35 & 55 & 39 & 51 & 42 & 48 \\
\hline 46 & 36 & 56 & 40 & 52 & 43 & 49 \\
\hline 47 & 37 & 57 & 47 & 53 & 44 & 50 \\
\hline 48 & 38 & 58 & 42 & 54 & 45 & 51 \\
\hline 49 & 39 & 59 & 43 & 55 & 46 & 52 \\
\hline 50 & 40 & 60 & 44 & 56 & 47 & 53 \\
\hline
\end{tabular}


-

2

0 
Table 2. Table of $\mathrm{x}^{2}$ values. ${ }^{1}$

\begin{tabular}{ccccccccc} 
d.f. & 0.50 & 0.40 & 0.30 & 0.20 & 0.10 & 0.05 & 0.01 \\
\cline { 2 - 8 } 1 & .455 & .708 & 1.07 & 1.64 & 2.71 & 3.84 & 6.63 \\
2 & 1.39 & 1.83 & 2.41 & 3.22 & 4.61 & 5.99 & 9.21 \\
3 & 2.37 & 2.95 & 3.67 & 4.64 & 6.25 & 7.81 & 11.3 \\
4 & 3.36 & 4.04 & 4.88 & 5.99 & 7.78 & 9.49 & 13.3 \\
5 & 4.35 & 5.13 & 6.06 & 7.29 & 9.24 & 11.1 & 15.1 \\
6 & 5.35 & 6.21 & 7.23 & 8.56 & 10.6 & 12.6 & 16.8 \\
7 & 6.35 & 7.28 & 8.38 & 9.80 & 12.0 & 14.1 & 18.5 \\
8 & 7.34 & 8.35 & 9.52 & 11.0 & 13.4 & 15.5 & 20.1 \\
9 & 8.34 & 9.41 & 10.7 & 12.2 & 14.7 & 16.9 & 21.7 \\
10 & 9.34 & 10.5 & 11.8 & 13.4 & 16.0 & 18.3 & 23.2 \\
\hline
\end{tabular}

IPortion of Percentage Points of the $\mathrm{X}^{2}$ Distribution Table. Ostle 1954, p.447, by permission of the author.

Table 3. Table of t-values. ${ }^{1}$

\begin{tabular}{lllll}
\hline & \multicolumn{4}{c}{$\alpha$} \\
\cline { 2 - 5 } d.f. $_{100}$ & 0.20 & 0.10 & 0.05 & 0.01 \\
200 & 1.290 & 1.661 & 1.984 & 2.626 \\
300 & 1.286 & 1.653 & 1.972 & 2.601 \\
400 & 1.284 & 1.650 & 1.968 & 2.592 \\
500 & 1.284 & 1.649 & 1.966 & 2.588 \\
1000 & 1.283 & 1.647 & 1.962 & 2.581 \\
\hline
\end{tabular}

I Portion of a Percentage Points of the $t$ Distribution Table. Ostle 1954, p.45I, by permission of the author. 
-

- 


\section{Literature Cited}

Blaisdell, J. P. and J. F. Pechanec 1949. Effects of herbage removals at various data on vigor of bluebunch wheatgrass and arrowleaf balsamroot. Ecol. 30(3):298-305.

Brazda, A. R. 1953. Elk migration and factors affecting movements in the Gallatin River Drainage, Montana. J. Wildl. Mgt. 17(1):9-23.

Costello, D. F. and G. E. Klipple 1939. Sampling intensity in vegetation surveys made by the square-foot density method. J. Amer. Soc. Agron, 31:800-810.

Evanco, A. B. and R. A. Peterson 1955. Comparisons of protected and grazed mount ain rangelands in southwestern Montana. Ecol. 36(1):71-82.

Heady, H. F. 1950. Studies on bluebunch wheatgrass in Montana and heightweight relationships of certain range grasses. Ecol. Monog. 20:55-81.

Ostle, Bernard 1954. Statistics in research. Iowa State College Press $487 \mathrm{pp}$.

Pechanec, J. F. and G. D. Pickford 1937. A weight estimate method for determination of range or pasture production. J. Amer. Soc. Agron. $54(10): 753-765$.

Snedecor, G. A. 1946. Statistical methods. Iowa State College Press. $485 \mathrm{pp}$. 
0

- 

